\title{
Value Orientation of China's New-Edition Kindergarten Job Directive Rules and Analysis of Kindergarten Governance
}

\author{
Cai Jun \\ School of Preschool Education, Xi'an University, Xi'an, China 710065 \\ caijun@xawl.edu.cn
}

Keywords: Kindergarten Job Directive Rules; Value orientation; Kindergarten governance

\begin{abstract}
Due to the special legal status of China's new edition of Kindergarten Job Directive Rules in the preschool education law system, the value orientation reflected by this revision provides design blueprint and legal protection for building a modern kindergarten governance system exerting supervision by the government and internal control by the kindergarten, and allowing parents to participate in, and is of important historical and practical significance for guiding preschool education of China in its new age to develop healthily and scientifically.

The document Kindergarten Job Directive Rules is of administrative regulations on preschool education with legal characteristics, legal basis for all activities of the kindergarten, and an important guarantee for strengthening kindergarten governance, increasing efforts to run and rule the kindergarten according to law. After regulations on preschool education released after the founding of new China, the Rules played a due important role in standardizing kindergarten job and guaranteeing the quality of kindergarten education in different times. The rules underwent four edition changes from Provisional Regulations for Kindergarten (Draft) proposed by the Ministry of Education in March 1952, Kindergarten Job Directive Rules (Trial) released in June 1989, Kindergarten Job Directive Rules issued for enforcement in March 1996 and the enactment of the kindergarten regulations and and new Kindergarten Job Directive Rules enforced formally in March 2016. In every revision of the Rules, the preschool education laws and regulations were improved and undated, policy decision makers re-examined education essence of the kindergarten and re-amended the interest demands, the value orientation of preschool education policies was presented in the text, and it reflected education policies adapted to the changes of preschool education practice and led the preschool practice changes. Therefore, in the new context of transformation from epitaxial development characterized by scale enlargement to connotative development characterized by quality improvement, as well as comprehensive reform of education, modernization of education governance, popularity of preschool education, and comprehensive promotion of managing education by law ${ }^{[1]}$, the new edition of Rules must present the value orientation that agrees with the time and the society based on meticulous observation and profound reconsidering of the education practice, and have the profound influence on the kindergarten governance.
\end{abstract}

\section{Status of the Rules in the Preschool Education Law System}

No legal regulations exist in isolation, as they are in corresponding logical relations with other legal regulations in the areas of content structure and effectiveness. After more than 60 years of practice and accumulation, the "vertical-horizontal 2D structured" socialist legal system with Chinese characteristics around the education law has been formed in China. The vertical dimension takes legal hierarchy as the standard covering six areas including terms on education in the constitution, basic law for education, specific laws for education, administrative regulations for education, education administrative rules and local education regulations and rules; the horizontal dimension takes adjusted contents as standard, covering the teachers' law, higher education law, vocational education law, private education law and law of academic degree.

Correspondingly, significant achievements have been made in the preschool education law system construction: for example, the constitution clearly puts forward "the nation shall develop 
preschool education", the education law states the nation shall implement the school education system including preschool education, the State Council approved special preschool education administrative regulations -- Kindergarten Management Regulations (1989) developed by the original State Education Commission, the Ministry of Education enacted preschool education rules -- Kindergarten Job Directive Rules (2016), and Kindergarten Education Guidelines (Trial) (2001), and all regions introduced various local preschool education rules and regulations, such as the Beijing Municipal Regulations on Preschool Education (2001), Basic Standards for Kindergarten Running in Shaanxi Province (Trial) (2011). It is true that because there is no preschool education sector law, the existing laws and regulations are not very effective with incomplete contents, the preschool education policy legal system is still not complete enough ${ }^{[2]}$; however, it is undeniable that its underlying architecture is increasingly clear and complete.

In the internal legal system, every legal norm is based on a legal system. Although legal norms are in connection with each other because of proximity of the adjusted contents, existence and functions of every legal norm cannot be completely replaced or canceled by other legal norms as they are independent, relatively autonomous with different roles in legal effectiveness and function; in addition, different ways of formulating laws and external expression forms of laws and regulations constitute legal norms at different hierarchies and have formed the longitudinal trunk of the legal system. Missing of any hierarchy in these hierarchies will restrict the implementation efficiency of the education law at its upper hierarchy. In the context of absence of preschool education laws, except the terms preschool education set forth in the constitution and the education law, the Regulations approved by the State Council is the only law special for preschool education, which aims to "strengthen kindergarten management", based on the macro system design such as "promoting the development of preschool education"; however, as education administrative rules released by the education sector of the State Council, the Rules was developed to implement the national laws and regulations on education. In terms of what it adjusts, it focuses on the relationship between government and the kindergarten and strengthening interior scientific management and standard operation of the kindergarten, with the aim to improve quality of child welfare and education, promote children's physical and mental health and conduct other specific matters. According to the legislative rules, laws and regulations at this hierarchy shall be enforceable and procedural rules on the laws at the upper hierarchy, showing the corresponding hierarchical relationship. Therefore, in terms of the relationship between laws and regulations, the document Rules is the implementing law of the Regulations. Although the document Rules is less effective than the Regulations, "it still has integrated effectiveness for enforcement countrywide" "[3].

It can be said, between the Regulations and the local preschool education rules, the Rules has provided specific basis for the local government to introduce preschool education rules with more targeted contents, bridged the gaps between the national administrative regulations and the local administrative regulations, and constituted an important hierarchy in the preschool education legal system, conducive to forming whole join forces for adjustment of the preschool education relationship, giving full play to its legal effectiveness and ensuring the legal subject's wills can be "practically" implemented with an indispensable role in the legal system in China.

\section{Value Orientation of the New-edition Rules}

Any legal norm pursues certain moral goals and follows certain values as the manifestation of social ethics in the law, besides, the formulation and requirements of legal norms at any hierarchy are under the control of specific guiding legal thoughts, principles or general value standards. The course of legal norms regulating people's behavior involves some ethical principles of the law, so meaning association between these regulations and law ideas can be mastered and expressed only by means of these principles ${ }^{[4]}$. Education laws, regulations and policies in different historical periods have different values. This is not only government decision-makers' subjective reflection to the knowledge of real education problems and choice of solutions, but also an objective reaction to the benefit structure relationship between social subjects in a certain historical period ${ }^{[5]}$. New revision of the Rules was made in the historical background of major developments and major 
changes in contemporary China, in the midst of basic transformation from making up difference in quantity to quality improvement, from site construction to team construction, and from undertaking development to child development. It shows common value elements in its legal system - fairness, democracy, freedom, equality and justice on the one hand, and on the other hand it also shows the unique value criterion held by the adjusted contents.

First , Coordination Between Body and Mind. Body is the material basis of psychology and psychology is the spiritual function of the body. Psychology and pedagogics, physiology and neuroscience have revealed from great significance of interaction and harmonious development between body and mind from different perspectives. There are two parts in the general principles of the new Rules added with "promoting children's physical and mental health" and "promoting children's mental health", which have put children's physical and mental health high to the level of aims and purposes, and the chapter "Health Care in Kindergarten" stresses the important significance of children's positive emotion for their physical and mental health, vividly interpreting that both starting point and end result of all education activities are to promote development of the educated.

Second, Subjectivity of Activities. Subjectivity is the form and characteristic of individual existence, including factors such as autonomy, independence and initiative. It's hard to imagine what it would be if there was non-subject or there is no subject, and it is hard to imagine whether passive or negative existence would be of any significance. ${ }^{[6]}$ As a social activity, kindergarten education should first highlight existence modes and unique positions of children in the activities. In emphasizing the principle of kindergarten education, the term "enlightenment and induction" in the old version was changed into "enlightenment and guidance". The change of one word reflects shift of children's subjective status from passive acceptance to active adaptation. The ethical principles in subjectivity of children's activity are also reflected in that children's age characteristics should be taken as the premise of activities, "encouraging and supporting children choose the game contents, game materials and partners independently according to their own interests, needs and level of experience, so that they get positive emotions during the game and comprehensively develop their abilities and personality."

Third , Inclusive Admissions. The inclusive education idea based on the philosophy of equity, equality and "zero refusal" rose in the late 1990s and gradually shifted from the call to include children with disabilities in the general education to the focus on including minorities, girls and other children in unfavorable conditions in general education, which has "become one of the main trends of special education in the world" "[7]. In the kindergarten enrollment, the new edition of Rules expands the educational assistance from children of the disabled and children of revolutionary martyrs to "orphans, needy children, disabled children with ability to receive general education", which requires the kindergarten to provide non-discriminatory, equal and inclusive education for all school-age children including special children in disadvantaged conditiions.

Fourth, study Involvement. Construction of children's experience world comes more from their personal involvement in the practice, from the children's interactions with the environment, which are their unique cognitive and learning styles. As Spanish philosopher Fernando Savater put, "In life, it is hard for us to avoid pleasant or painful run in with the world. In fact, most of the basic knowledge we have was acquired this way." ${ }^{[8]}$ The new edition of Rules specifically suggests focusing on "direct perception, actual operation and firsthand experience" in children's learning process.

Fifth , Educational Meaning of Environment. After Locke's "theory of tabula rasa" revealed the secret of environment impact on children's development, all genetic predeterminism, environmental determinism and theory of convergence do not deny the significance of the environment for human education. Maria Montessori stressed the prepared environment was a prerequisite for child development, and efforts should be made actively to build free, orderly, real, natural, aesthetic and safe material and spiritual environment for children. The new edition of Rules regards environment as important education resources and requires to reasonably use the environment inside and outside the classroom to create open and diverse spaces for activities, 
provide abundant toys, operation materials and children's books that are suitable for children's age, support children to choose independently and and learn actively, and inspire children's interest in learning and desire to explore; in addition, the new edition of Rules also stresses the important significance of psychological environment and requires the kindergarten to establish a respectful, receptive and caring environment and establish good companionship and good relationship between students and teachers.

Sixth , Processness of Evaluation. The conception of modern education evaluation is increasingly aware that knowledge and education have their intrinsic value and inherent perfect standards, so there is no need to prove by the education results ${ }^{[9]}$. Evaluation of results will stray from the evaluation object and the purpose, thus turning to seeking "flowers without roots." Individual differences in children's development and their age characteristics determine that the evaluation of their activities needs to respect the process itself rather than the results. The new edition of Rules was explicitly supplemented with "the process of education activities should focus on supporting the children's initiative exploration, operating practices, cooperation, communication and expression, rather than one-sided pursuit of activity outcomes".

\section{Structure of Modern Kindergarten Governance System Required by the New Rules}

The value orientation is the spirit core, ideal form, and theoretical implication of the preschool education laws and regulations, while the kindergarten governance system developed based on that is the physical shell, real structure and practical purpose of the preschool education laws and regulations.

Traditional kindergarten management, from macro to micro, generally includes government's management of kindergartens, internal affairs management of kindergartens and classroom management by teachers. Management is mainly carried out mainly for the internal kindergarten; governance in the modern sense indicates how an organization works, which is a process, a kind of constant interaction, based on coordination, involving both public and private sectors ${ }^{[10]}$, and requiring coordination of the relationships between the different elements within the kindergarten, as well as coordination of the relationships between the government, the kindergarten and the family. The new edition of Rules provides policy guidance for transforming the government function, optimizing internal standardized management of the kindergarten and strengthening home-kindergarten co-education home education has done a policy guide, which is a positive exploration for building a modern kindergarten governance system.

\section{The Government Turns from the Kindergarten Operational Guidance to Comprehensive Supervision}

The new edition of Rules shows that the government turns to comprehensive supervision of program duration, funds, assets and information from focusing on kindergarten guidance in nursing care and education. This shift in regulatory functions is mainly shown in the following areas:

First, permitting for-profit private kindergartens. Words "No organization or individual shall run a kindergarten to make profits" were removed from the new Rules, which agrees with the spirit of second review of the draft amendment to the law for promotion of private education based on comments from the public widely solicited via www.npc.gov.cn, that is, non-governmental educational institutions will be subject to tailored guidance and private schools can choose to be for-profit or nonprofit independently.

Second, strengthening Party organization construction in the kindergarten. The new edition of Rules suggests "giving full play to the political core role of the party organizations and the fighting bastion role", and adhering to the policy of strengthening moral education and cultivating people, only by this way can the Party's educational principle and policy be faithfully executed and the children improve in terms of their moral, intellectual and fitness level as well as in their appreciation of aesthetics.

Shifting from Extensive Control to lean Control in the Kindergarten

With the vigorous development of preschool education and dramatic social revolution, there are new requirements for functions, security, teachers and sizes of kindergartens, making the internal 
management of the kindergarten leaner. Specifically, there are points as follows amended in the new Rules:

First, deepening of the traditional functions of kindergartens. For a long time, giving young children nursing care and education as well as providing convenience for parents to work and study have been two major tasks and functions of the kindergarten. As the special value of the preschool education is increasingly remarkable and there are changes in parental perception, as specialized social institutions for preschool education kindergartens not only share the burden of parents in raising beyond providing good good nursing care and education services, but also need to assume the social responsibility of "providing scientific parenting guidance for parents of children".

Second, highlighting the kindergarten safety. In view of the various security incidents occurred frequently in recent years to kindergartens, which have caused greater harm to children's physical and mental health and their growth, a chapter "Safety of Kindergarten"was specially added to the new Rules, with explicit provisions in completing safety management system, safety of facilities in the kindergarten, food and drug safety, children's safety education, anti-domestic violence, school liability insurance, and other areas.

Third, raising access standards of caregivers and teachers. With transformation of preschool teacher education and culture system in China and demand of the society for highly educated preschool teachers, the new edition of Rules raises the access standards of kindergarten caregivers and teachers. For example, it requires the kindergarten principal to have a college degree or above with three years of experience in kindergarten job. The provisions on work experience help to put an end to arbitrary appointment of kindergarten principals in kindergartens affiliated to enterprises and public institutions as well as private-owned kindergartens, ensuring the kindergarten's management team are specialized.

Fourth, limiting the size of kindergartens. Due to the characteristics of the children enrollment in a nearby school, a well-laid out kindergarten public service system in a modest size can best meet the needs of school-age children. To "downsize" the kindergarten is to reduce pressure of teachers and improve quality and effectiveness of kindergarten management quality, and protect the education resources enjoyed by all children students.

Fifth, forbidding tendency of kindergarten education toward primary school. To eliminate the tendency of kindergarten education toward primary school has been a strong demand in the academic community, and local governments have also issued documents against the tendency of kindergarten education toward primary school, but due to limitation of the legal effect and multiple pressures from parents and the society, the elimination of such tendency is always reluctantly carried out in a disguised manner, receiving little evident effect As the education regulations issued by the national competent administrative department for education, the new edition of Rules expressly prohibits kindergartens from teaching primary school education content in advance and prohibits organizing "any activity that is against children's mental and physical development". Its binding force will be significantly enhanced.

\section{Wider and Deeper Participation and Cooperation of and between Family and Kindergarten}

One important strategy for adjusting the relationship between schools and the society is that the parents get invoved in school management ${ }^{[11]}$, which is also one of the important paths for building the modern school system. This revision expands the parents' right to know, participate in, make suggestions and make decisions in respect of, the kindergarten job, marking important progress of the kindergarten government system modernization.

First, the parents' right to know the kindergarten is expanded. The new edition of Rules requires that the kindergarten should disclose its charges collectable, charging standards and weekly recipes for children of the kindergarten to parents, release the meal expense account to parents every month, and accept social supervision; "should establish an open day system for parents" to deliver the kindergarten culture, nursing care and education characteristics and educational philosophy.

Second, the parents' right to participate and make suggestions is expanded. The new edition of Rules points out that one of the main tasks of the nd parents of kindergarten is one of the main tasks 
of the parent committee is to put forward comments and suggestions for important decisions of the kindergarten and matters related to children's interests, and help the kindergarten carry out family education guidance and communication.

Third, the kindergarten committee meeting grants parents preliminary decision making rights. The new edition of Rules requires that the kindergarten "should" establish a kindergarten committee including representatives of children's parents. The kindergarten committee meeting should review establishment, amendment and termination of rules and regulations, kindergarten job plan, work summary, staff rewards, financial budget and final accounts plans, as well as other important issues concerning the kindergarten job.

In conclusion, due to the special legal status of the new edition of Rules in the preschool education law system, the ethical principles of the law reflected by this revision provides design blueprint and legal protection for building a modern kindergarten governance system exerting supervision by the government and internal control by the kindergarten, and allowing parents to participate in, and is of important historical and practical significance for guiding preschool education in the new age to develop healthily and scientifically.

\section{References}

[1] [Cai Jun. Survival and Improvement of Laid-off Teachers of Kindergartens in Rural Areas [J]. Studies in Preschool Education, 2015, (5): 10-14.

[2] Pang Lijuan, Xia Jing, Han Xiaoyu. Research on Hong Kong Infant Teacher Laws and Policies: Characteristics and Implications [J]. Teacher Education Research, 2011, (1): 49-54.

[3] Li Enci, On the Education Legal System in China [J]. Journal of Capital Normal University (Natural Science Edition), 2001 (1): 102-110.

[4] Shu Guoying. Meditations on Philosophy of Law [M.], Beijing: Peking University Press, 2010:173.

[5] Liu Shiqing. Study on the Ethical Problems of Education Policies [D]. Shanghai: East China Normal University, 2007.

[6] Guo Zhan. Philosophy of Subjectivity -- Human Existence and Its Significance [M]. Kunming: Yunnan People's Publishing House, 2002:292.

[7] Deng Meng, Xiao Fei. Philosophical Basis of Inclusive Education: Criticism and Reconsideration [J]. Educational Research and Experiment, 2008, (5). 18-22.

[8] [Spanish] Fernando Savater. The Value of Education [M]. Beijing: Peking University Press, 2012:10.

[9] Li Yanbing. Theory of Curriculum Evaluation [M]. Shanghai: Shanghai Education Publishing House, 2002:113.

[10] Yu Keping. Governance and Good Governance [M]. Beijing: Social Sciences Academic Press, 2000:3-4.

[11] Man Jianyu.On Construction of the Parent Committee in the Modern School Governance System [J]. Journal of the Chinese Society of Education, 2014, (9): 44-47. 